\title{
Pre-Operative Sildenafil for Patients With Pulmonary Hypertension Undergoing Mitral Valve Surgery: A Systematic Review and Meta-Analysis
}

\author{
Danielle Louis E. Villanueva ${ }^{\mathrm{a}, \mathrm{b}}$, Ruth Divine Agustin ${ }^{\mathrm{a}}$, Elmer Jasper Llanes ${ }^{\mathrm{a}}$
}

\begin{abstract}
Background: Pulmonary hypertension is a usual complication of long-standing mitral valve disease. Perioperative pulmonary hypertension is a risk factor for right ventricular failure and is an important cause of morbidity and mortality in patients with pulmonary hypertension undergoing mitral valve surgery. Phosphodiesterase-5 inhibitors particularly sildenafil citrate have proven clinical benefit for pulmonary arterial hypertension but have shown discordant results in group 2 pulmonary hypertension patients. We sought to determine the effect of pre-operative sildenafil on the intra-operative hemodynamic parameters of these patients.
\end{abstract}

Methods: Studies were included if they satisfied the following criteria: 1) Randomized controlled trials; 2) Adult patients with pulmonary hypertension scheduled for elective mitral valve surgery; and 3) Reported data on changes in pre-, intra-, and post-operative hemodynamic parameters. Using PUBMED, Clinical Key, Science Direct, and Cochrane databases, a search for eligible studies was conducted from September 1 to December 31, 2018. The quality of each study was evaluated using the Cochrane Risk of Bias Tool. The primary outcome of interest is on the effect of pre-operative sildenafil on the improvement of intra-operative hemodynamic parameters such as systolic pulmonary artery pressure (sPAP), mean pulmonary arterial pressure, mean arterial pressure, pulmonary and systemic vascular resistances. We also investigated its effect on the post-operative mortality, length of cardiopulmonary bypass time, ventilation time, and inotrope support requirement. Review Manager 5.3 was utilized to perform analysis of random effects for continuous outcomes.

Results: We identified three studies involving 153 patients with pulmonary hypertension undergoing mitral valve surgery, showing that among those who received pre-operative sildenafil there is a significant decrease in intra-operative systolic pulmonary arterial pressure

Manuscript submitted October 7, 2019, accepted October 21, 2019

aDivision of Cardiovascular Medicine, University of the Philippines, Philippine General Hospital, Manila 1000, Philippines

${ }^{\mathrm{b}}$ Corresponding Author: Danielle Louis E. Villanueva, Division of Cardiovascular Medicine, University of the Philippines, Philippine General Hospital, Taft Avenue, Manila 1000, Philippines.

Email: louievillanuevamd@gmail.com

doi: https://doi.org/10.14740/cr962 (mean difference -11.19 (95\% confidence interval (CI), -20.23 to $-2.15), \mathrm{P}<0.05$ ) and post-operative sPAP (mean difference -13.67 $(95 \% \mathrm{CI},-19.56$ to -7.78$), \mathrm{P}<0.05)$ without significantly affecting the mean arterial pressure (mean difference 1.94 (95\% CI, -5.49 to 9.37), $\mathrm{P}<0.05)$. The systemic and pulmonary vascular resistances were not affected as well.

Conclusions: Administration of pre-operative sildenafil to patients with pulmonary hypertension undergoing mitral valve surgery decreases intra-operative and post-operative systolic pulmonary arterial pressure without significantly affecting other systemic hemodynamic parameters.

Keywords: Sildenafil; Severe pulmonary hypertension; Mitral valve surgery

\section{Introduction}

Pulmonary hypertension $(\mathrm{PH})$ is defined as an increase in mean pulmonary arterial pressure $(\mathrm{mPAP}) \geq 25 \mathrm{~mm} \mathrm{Hg}$ at rest as assessed by right heart catheterization (RHC) [1]. In the latest classification, there are five groups of $\mathrm{PH}$ depending on its etiology. The most common cause of $\mathrm{PH}$ worldwide is group $2 \mathrm{PH}$ from left heart disease (LHD-PH) [1], and valvular heart disease (VHD) is amongst the leading causes of this type of secondary $\mathrm{PH}[2]$.

PH affects virtually all patients with severe symptomatic mitral valve disease and up to $65 \%$ of those with symptomatic aortic stenosis [3]. Mitral and aortic valve diseases increase left atrial pressure which, in turn, leads to an initially passive and potentially reversible increase in pulmonary pressures. Vascular injury then triggers a cascade of venous and small artery remodeling, non-reversible arterial $\mathrm{PH}$, and eventually, right ventricular dysfunction [4].

Cardiac surgery in patients with VHD with severe pulmonary arterial hypertension (PAH) is often complicated with right ventricular (RV) failure with an adverse consequence on its prognosis [5, 6]. Right ventricle is susceptible to ischemic injury, as cardiopulmonary bypass (CPB) exacerbates PAH [7]. This necessitates perioperative strategy to manage PAH and RV dysfunction. This goal should be achieved without compromising systemic blood pressure and coronary perfusion [8]. 
In a large study on patients who underwent mitral valve operation, both operative mortality and long-term survival were correlated with the degree of pre-operative PH. Hence, pre-operative pulmonary artery systolic pressure is a powerful predictor of early and late survival after mitral valve operation [9].

Sildenafil, a phosphodiesterase-5 (PDE5) inhibitor, has a relaxant effect on the pulmonary vascular smooth muscle thereby lowering the pulmonary artery pressure and pulmonary vascular resistance in patients with various forms of $\mathrm{PH}$ $[9,10]$. It has a proven clinical efficacy in PAH [11], but has shown discordant results in the field of LHD-PH [12-16].

In contrast to pediatric patients where there have been reports of significant benefit of pre-operative administration of sildenafil prior to congenital heart disease surgery, there has been little experience with the use of oral sildenafil in adult cardiac surgical patients with $\mathrm{PH}$. Trachte et al reported a beneficial effect of oral sildenafil in patients with $\mathrm{PH}$ in the perioperative period. Although they reported a statistically significant effect on mean systemic arterial blood pressure, it was clinically insignificant [17]. There are also reports of its use in the post-operative period. In the setting of VHD, short-term studies have shown favorable effects of the drug in the immediate phases after surgery [18].

In the Sildenafil for Improving Outcomes in Patients With Corrected Valvular Heart Disease and Persistent Pulmonary Hypertension: A Multicenter, Double-Blind, Randomized Clinical Trial (SIOVAC Trial) [19], post-operative administration of sildenafil failed to improve long-term outcomes of patients with residual $\mathrm{PH}$ after valvular surgery. Contrary to the expected findings, more patients in the sildenafil group had a worse composite clinical score at the sixth month than at the start of the study (odds ratio for improvement, $0.39 ; 95 \%$ confidence interval (CI), 0.22 - 0.67; P < 0.001) [19].

However, there were some trials on the potential benefit of pre-operative administration of sildenafil among those with $\mathrm{PH}$ from LHD. Three randomized trials demonstrated a significant lowering of the pulmonary pressures intra-operatively. In 2006, Shim et al [20] drew a randomized prospective double-blind study on the effect of oral sildenafil on the pulmonary artery systolic pressure in patients undergoing cardiac surgery where sildenafil produced significant pulmonary vasodilatory effect relative to placebo in anesthetized cardiac surgical patients with PH. This was followed by a 2012 study by Ayyad et al [21] among patients with $\mathrm{PH}$ undergoing elective mitral valve replacement. They observed a similar trend of lowering the intraoperative systolic pulmonary artery pressure (sPAP) after immediate pre-operative administration of sildenafil without affecting the other hemodynamic parameters. Administration of sildenafil three times a day $24 \mathrm{~h}$ prior to the schedule of surgery also showed significant lowering of the intra-operative pulmonary pressures and decrease in inotrope requirement post-operatively among patients with severe pre-operative $\mathrm{PH}$ undergoing mitral valve surgery [22]. These three small trials have shown that preoperative administration of sildenafil has a significant effect on the intra-operative parameters among these patients.

Since these three trials are suggesting that pre-operative administration of sildenafil has a benefit for patients with $\mathrm{PH}$ undergoing valvular heart surgery, we aim to synthesize the available evidence to determine the effect of pre-operative ad- ministration of sildenafil on the intra-operative parameters of patients with $\mathrm{PH}$ undergoing valvular heart surgery.

\section{Materials and Methods}

\section{Research question}

This study aims to show the effect of pre-operative administration of sildenafil on cardiovascular mortality, intra-operative and post-operative hemodynamic parameters and post-operative outcomes among adult patients with $\mathrm{PH}$ undergoing mitral valve surgery.

\section{Objectives}

We aim to determine the effect of pre-operative sildenafil on cardiovascular mortality, on intra-operative and post-operative and on the duration of cardiopulmonary bypass and ventilation time among adult patients with $\mathrm{PH}$ undergoing mitral valve surgery.

\section{Selection criteria}

Studies were included in the meta-analysis if they satisfied the following inclusion criteria: 1) Randomized controlled trials; 2) Adult patients with $\mathrm{PH}$ from left-sided heart disease undergoing mitral valve surgery; and 3) Reported data on cardiovascular mortality, changes in intra-operative and post-operative hemodynamic parameters, and improvement in cardiopulmonary bypass and ventilation times. Studies among pediatric patients, patients with congenital heart disease, patients with pre-operative left and RV dysfunction, those undergoing a concomitant cardiac procedure other than valve surgery, and those with significant pulmonary, hepatic and renal impairment will not be included.

\section{Literature search}

The two authors of this review independently performed a systematic computer search in the Pubmed, Science Direct, Medline, Clinical Trials, and Cochrane Central Register of Controlled Trials databases for eligible studies (from September to December 2018) using a combination of the following search terms: "sildenafil", "sildenafil citrate", "cardiac surgery", and "pulmonary hypertension”. No language, data, or publication restrictions will be imposed.

\section{Data collection and quality assessment}

The identified studies were evaluated independently by the authors to determine their relevance for full text retrieval. The eligibility of the studies was then assessed by two independent reviewers (DLV and RDA) according to the specified inclusion 


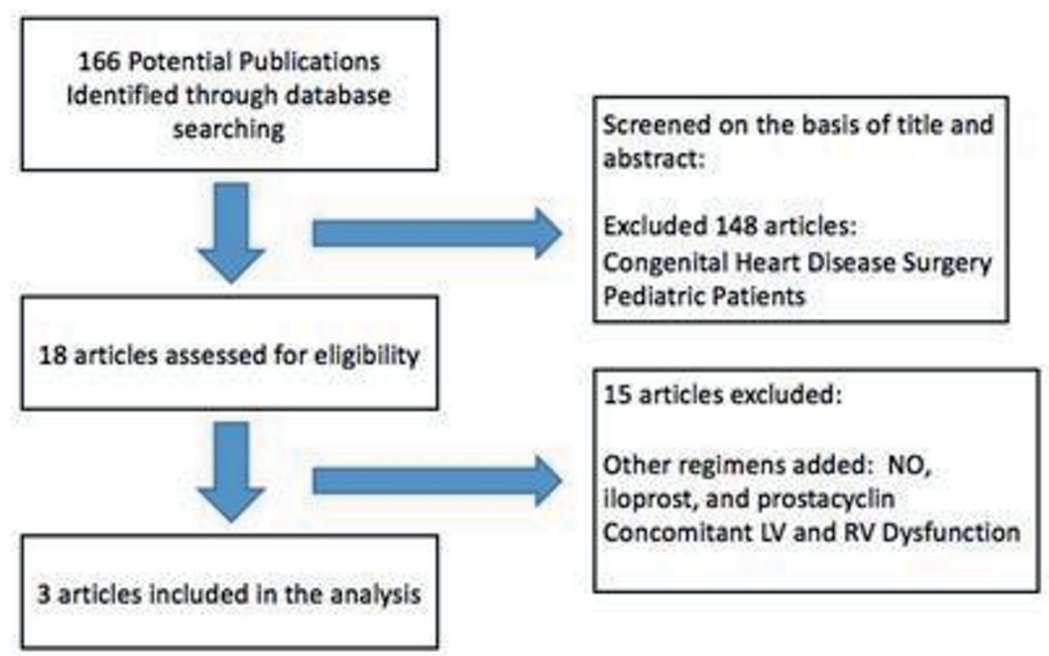

Figure 1. PRISMA flow diagram of study screening and selection. PRISMA: Preferred Reporting Items for Systematic Reviews and Meta-Analyses.

criteria. Each study that fulfilled the inclusion criteria was assessed of methodological quality using the Cochrane Risk of Bias Tool for Randomized Clinical Trials. Reasons for exclusion were documented. Disagreements were resolved by discussion with a third author. The author/s, year published, study design, population characteristics, sample size, interventions, and outcomes were extracted from each study. Disagreements were again resolved by discussion with the third author.

\section{Data analysis}

Meta-analysis was conducted using the inverse variance random-effects model for continuous outcomes to generate mean differences, 95\% CIs, and forest plots. For dichotomous outcomes, we used the Mantel-Haenzel random-effects model to generate risk ratios (RRs), 95\% CIs, and forest plots. Heterogeneity was assessed through the Chi-square and $\mathrm{I}^{2}$ test. All statistical analyses were carried out using Review Manager (RevMan) version 5.3 (The Nordic Cochrane Centre, The Cochrane Collaboration, Copenhagen).

\section{Results}

\section{Output of literature search}

Our systematic literature search (Fig. 1) yielded a total of three articles involving 153 patients for inclusion in this review.

The following is the description of the included studies. Table 1 summarizes the characteristics and details of the included studies [20-22]. All studies were conducted in different tertiary hospitals. In the study by Ayyad et al [21], the mean age was $32 \pm 10.4$ years with more women in the placebo group; in the study by Gandhi et al [22], the mean age was $38.79 \pm 8.62$ years with $50 \%$ men; and in the study by Shim et al [20], the mean age was $50 \pm 11.5$ years with $39 \%$ men. Almost all the patients in the three studies underwent elective mitral valve replacement due to either mitral stenosis or mitral regurgitation. However, in the study by Shim et al, there were 11 cases of concomitant aortic valve repair/replacement but it was not statistically different between the two treatment groups. The baseline pre-operative sPAP was measured by transthoracic echocardiography in the three studies. The intra-operative and post-operative hemodynamic parameters were measured via a pulmonary artery catheter. Measurement of these intra-operative variables was done $30 \mathrm{~min}$ to $1 \mathrm{~h}$ after induction of anesthesia and the post-operative measurement was done $1 \mathrm{~h}$ after cardiopulmonary bypass. The surgical technique was standard in the three studies. Two studies reported outcomes on mortality, cardiac bypass time, inotrope requirement, and ventilation time.

\section{Quality assessment of included studies}

We have included three good quality studies in this study (Fig. 2). All three studies were double-blind randomized controlled trials except for the study by Ayyad et al, which did not report allocation concealment and blinding of the personnel. Only the study by Shim et al mentioned that the outcome assessors were blinded to the outcomes measured. All three studies reported completed data and there were no drop-outs.

\section{Results on the outcome of interest}

\section{Change in $S P A P$}

The analysis of the three studies (Fig. 3) showed that preoperative sildenafil administration significantly decreased the pre-operative systolic pressure by a mean difference of 11.19 $\mathrm{mm} \mathrm{Hg}(95 \% \mathrm{CI},-20.23$ to -2.15 ; $\mathrm{P}<0.05)$ during the intra- 
Table 1. Summary of Included Studies

\begin{tabular}{|c|c|c|c|c|}
\hline $\begin{array}{l}\text { Study title, study design, au- } \\
\text { thor, and year of publication }\end{array}$ & $\begin{array}{l}\text { Population and } \\
\text { study design }\end{array}$ & Intervention & $\begin{array}{l}\text { Hemodynamic pa- } \\
\text { rameters measured }\end{array}$ & $\begin{array}{l}\text { Other outcomes } \\
\text { reported }\end{array}$ \\
\hline $\begin{array}{l}\text { Effect of immediate pre-operative } \\
\text { oral sildenafil administration for } \\
\text { pulmonary hypertension in patients } \\
\text { undergoing mitral valve replacement } \\
\text { (Ayyad et al, 2012) [21] }\end{array}$ & $\begin{array}{l}\text { Sixty adult patients with } \\
\text { mean sPAP } 75.3 \mathrm{~mm} \mathrm{Hg} \\
\text { scheduled for elective } \\
\text { mitral valve replacement, } \\
\text { double-blind randomized } \\
\text { controlled trial }\end{array}$ & $\begin{array}{l}\text { Group A: sildenafil } \\
25-50 \mathrm{mg} \\
\text { (according to } \\
\text { weight) given } 60 \\
\text { min before induction } \\
\text { of anesthesia; } \\
\text { group B: placebo }\end{array}$ & $\begin{array}{l}\text { Systemic blood } \\
\text { pressure; pre-operative } \\
\text { echocardiography; } \\
\text { sPAP: pre-, intra-, } \\
\text { and post-operative; } \\
\text { CVP: pre-, intra-, } \\
\text { and post-operative }\end{array}$ & None \\
\hline $\begin{array}{l}\text { Effect of pre-operative oral } \\
\text { sildenafil on severe pulmonary } \\
\text { arterial hypertension in patients } \\
\text { undergoing mitral valve replacement } \\
\text { (Gandhi et al, 2014) [22] }\end{array}$ & $\begin{array}{l}\text { Forty adult patients } \\
\text { with RVSP } \geq 50 \mathrm{~mm} \mathrm{Hg} \\
\text { scheduled for elective } \\
\text { mitral valve replacement, } \\
\text { double-blind randomized } \\
\text { controlled trial }\end{array}$ & $\begin{array}{l}\text { Group A: sildenafil } \\
25 \mathrm{mg} \text { given three } \\
\text { times a day for } 24 \mathrm{~h} \\
\text { before the surgery; } \\
\text { group B: placebo }\end{array}$ & $\begin{array}{l}\text { Mean arterial } \\
\text { pressure, pre-operative } \\
\text { echocardiography; } \\
\text { sPAP, mPAP, SVR } \\
\text { and PVR: pre-, intra-, } \\
\text { and post-operative }\end{array}$ & $\begin{array}{l}\text { Bypass time, cross- } \\
\text { clamp time, inotrope } \\
\text { requirement post- } \\
\text { operative, ventilation } \\
\text { time, post-operative } \\
\text { recovery stay, mortality }\end{array}$ \\
\hline
\end{tabular}

SPAP: systolic pulmonary artery pressure; CVP: central venous pressure; RVSP: right ventricular systolic pressure; mPAP: mean pulmonary artery pressure; PVR: pulmonary vascular resistance; SVR: systemic vascular resistance.

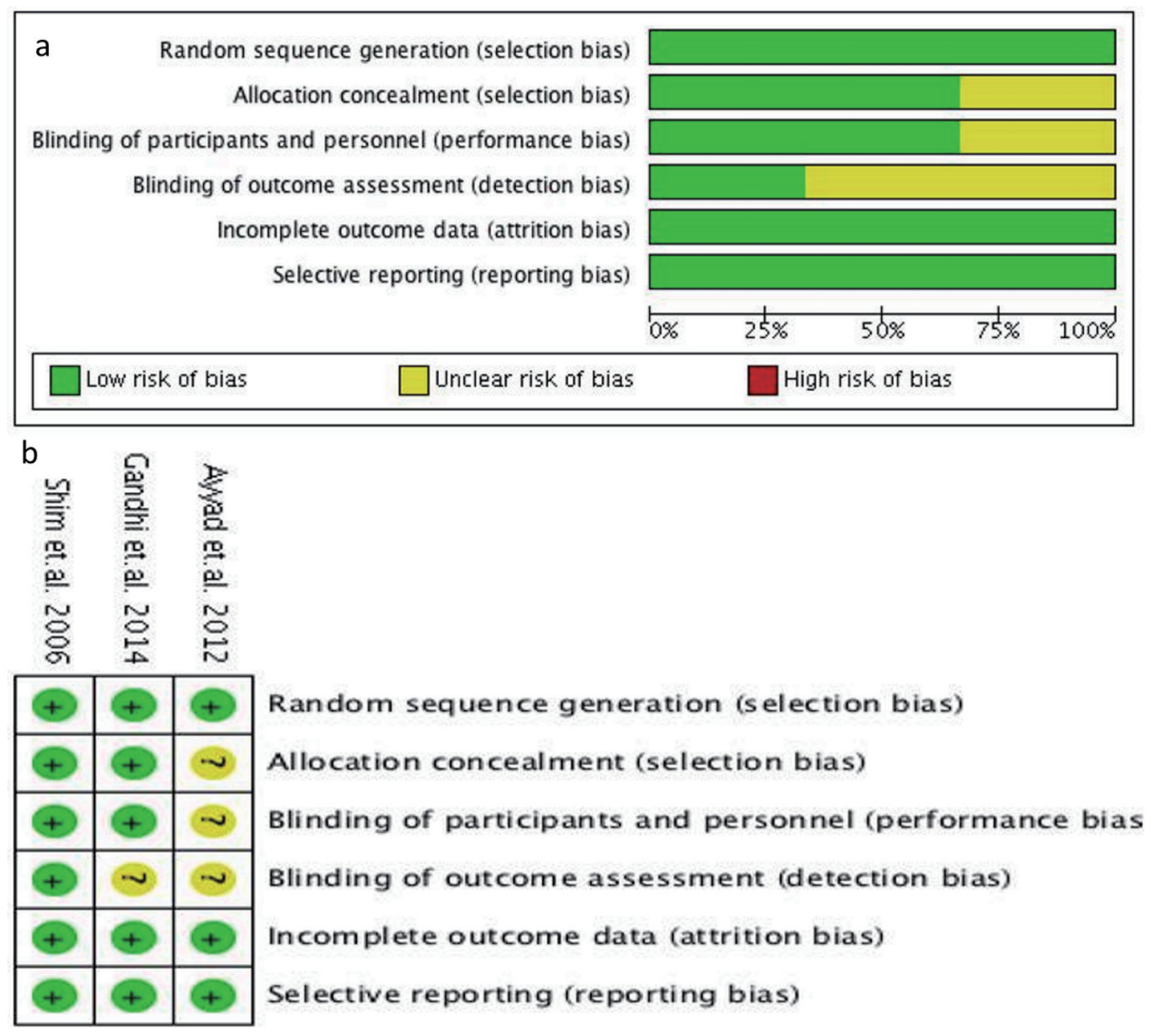

Figure 2. Cochrane risk of bias assessment tool (a), and Cochrane risk of bias assessment summary (b). 


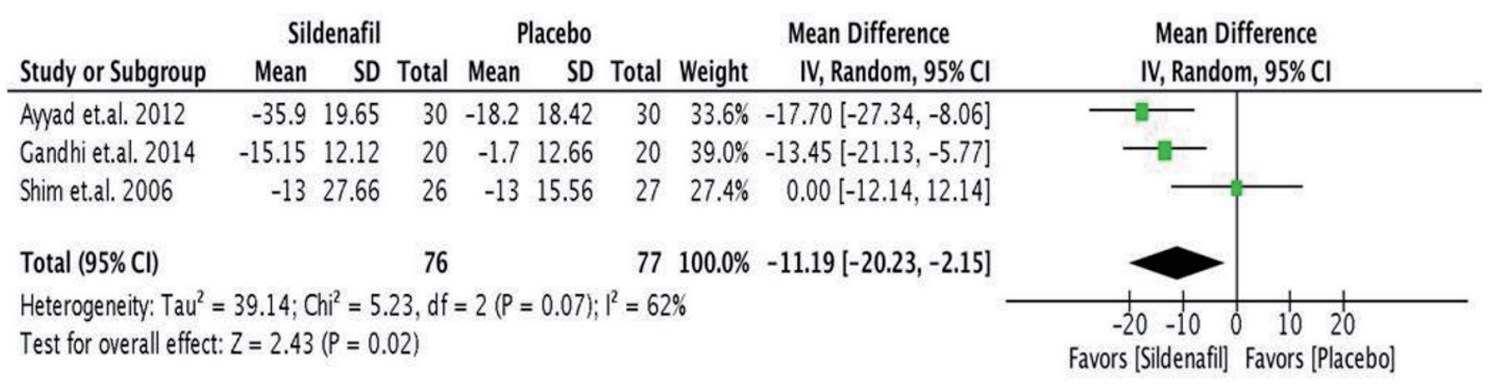

Figure 3. Forest plot showing the mean difference between pre- and intra-operative SPAP in the sildenafil and placebo groups. SPAP: systolic pulmonary artery pressure.

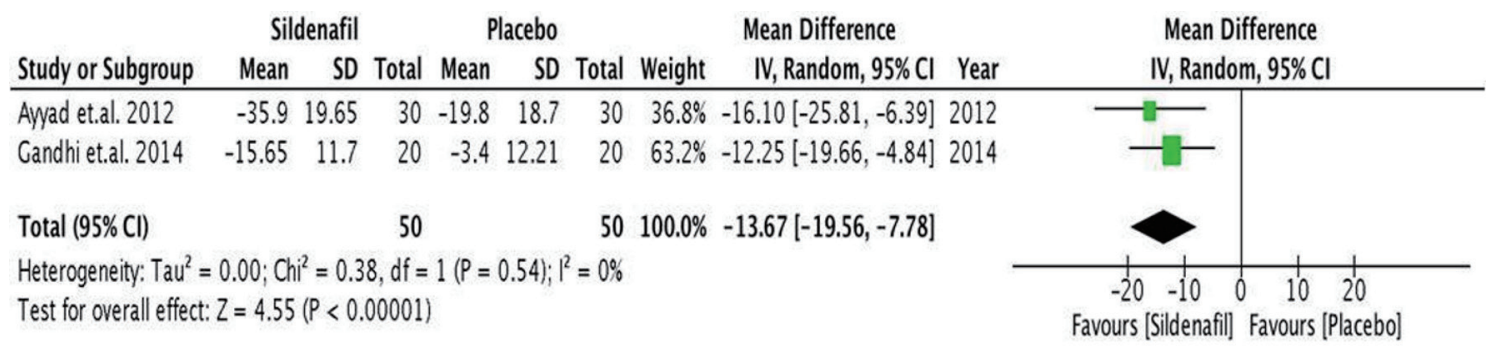

Figure 4. Forest plot showing the mean difference between pre- and post-operative SPAP in the sildenafil and placebo groups. sPAP: systolic pulmonary artery pressure.

operative period. There was moderate degree of heterogeneity with an $\mathrm{I}^{2}$ value of $62 \%$.

A similar trend was seen in the analysis (Fig. 4) of the post-operative systolic pressure. It was shown that the significant decrease in the pre-operative sPAP to a lower value in the intra-operative persisted to the post-operative period (after 1 $\mathrm{h}$ in the recovery room) with a significant mean difference of
$13.67 \mathrm{~mm} \mathrm{Hg}(95 \% \mathrm{CI},-19.56$ to $-7.78 ; \mathrm{P}<0.05)$. There was no heterogeneity reported.

Change in mean pulmonary artery pressure (mPAP)

Only two studies reported intra-operative mPAP. In the

\begin{tabular}{|c|c|c|c|c|c|c|c|c|c|}
\hline \multirow[b]{2}{*}{ Study or Subgroup } & \multicolumn{3}{|c|}{ Sildenafil } & \multicolumn{3}{|c|}{ Placebo } & \multicolumn{2}{|r|}{ Mean Difference } & \multirow{2}{*}{$\begin{array}{c}\text { Mean Difference } \\
\text { IV, Random, } 95 \% \mathrm{Cl}\end{array}$} \\
\hline & Mean & SD & Total & Mean & SD & Total & Weight & IV, Random, $95 \% \mathrm{Cl}$ Year & \\
\hline Shim et.al. 2006 & -8 & 10.63 & 26 & -8 & 17.69 & 27 & $47.6 \%$ & $0.00[-7.82,7.82] 2006$ & \\
\hline Candhi et.al. 2014 & -12.62 & 6.49 & 20 & 1.53 & 11.27 & 30 & $52.4 \%$ & $-14.15[-19.08,-9.22] 2014$ & - \\
\hline Total $(95 \% \mathrm{Cl})$ & & & 46 & & & & $100.0 \%$ & $-7.41[-21.26,6.44]$ & \\
\hline $\begin{array}{l}\text { Heterogeneity: Tau } \\
\text { Test for overall effect }\end{array}$ & $\begin{array}{l}=88.97 ; \\
Z=1.05\end{array}$ & $\begin{array}{l}-h i^{2}=8 . \\
(P=0 .\end{array}$ & $\begin{array}{l}.99, \mathrm{df}= \\
29)\end{array}$ & $=1($ & & B); $;\left.\right|^{2}=8$ & & & $\begin{array}{ccccc}1 & 1 & 1 & 1 \\
-50 & -25 & 0 & 25 & 50 \\
\text { Favours [Sildenafil] } & \text { Favours [Placebo }\end{array}$ \\
\hline
\end{tabular}

Figure 5. Forest plot showing the mean difference between pre- and intra-operative MPAP in the sildenafil and placebo groups. mPAP: mean pulmonary artery pressure.

\begin{tabular}{|c|c|c|c|c|c|c|c|c|c|}
\hline \multirow[b]{2}{*}{ Study or Subgroup } & \multicolumn{3}{|c|}{ Sildenafil } & \multicolumn{3}{|c|}{ Placebo } & \multicolumn{2}{|r|}{ Mean Difference } & \multirow{2}{*}{$\begin{array}{l}\text { Mean Difference } \\
\text { IV, Random, } 95 \% \mathrm{Cl}\end{array}$} \\
\hline & Mean & SD & Total & Mean & SD & Total & Weight & IV, Random, $95 \% \mathrm{Cl}$ Year & \\
\hline Shim et.al. 2006 & -82 & 198.01 & 26 & -51 & 93.44 & 27 & $50.8 \%$ & $-31.00[-136.44,74.44] 2006$ & \\
\hline Candhi et.al. 2014 & -27.85 & 113.73 & 30 & -41.71 & 76.64 & 30 & $49.2 \%$ & $13.86[-93.17,120.89] 2014$ & \\
\hline Total $(95 \% \mathrm{Cl})$ & & & 56 & & & 57 & $100.0 \%$ & $-8.91[-84.02,66.21]$ & \\
\hline \multicolumn{9}{|c|}{$\begin{array}{l}\text { Heterogeneity: } \operatorname{Tau}^{2}=0.00 ; \mathrm{Chi}^{2}=0.34, \mathrm{df}=1(P=0.56) ; l^{2}=0 \% \\
\text { Test for overall effect: } Z=0.23(P=0.82)\end{array}$} & $\begin{array}{lllll}-500 & -250 & 0 & 250 & 500 \\
\text { Favours [SIldenafil] Favours [Placebo] }\end{array}$ \\
\hline
\end{tabular}

Figure 6. Forest plot showing the mean difference between pre- and intra-operative PVR in the sildenafil and placebo groups. PVR: pulmonary vascular resistance. 


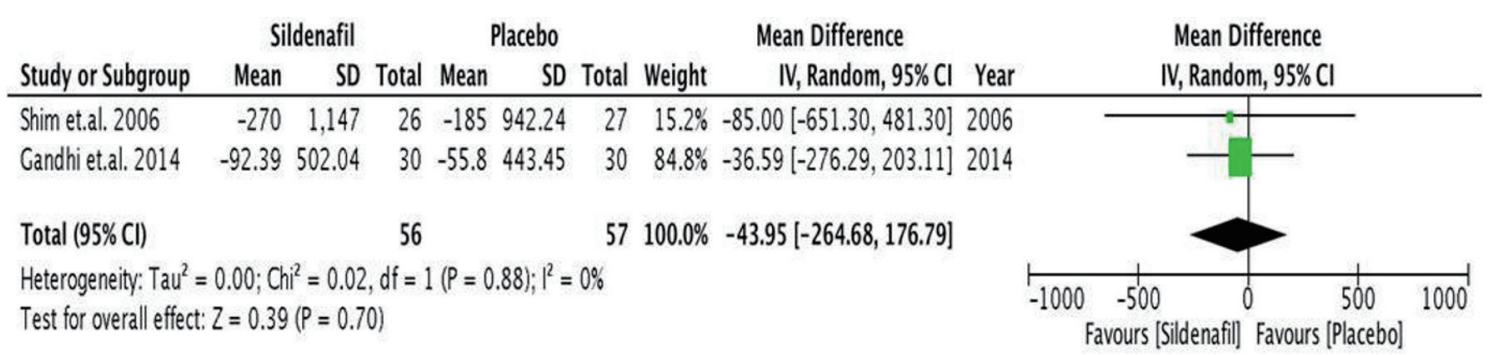

Figure 7. Forest plot showing the mean difference between pre- and intra-operative SVR in the sildenafil and placebo groups. SVR: operative systemic vascular resistance.

\begin{tabular}{|c|c|c|c|c|c|c|c|c|c|c|}
\hline \multirow[b]{2}{*}{ Study or Subgroup } & \multicolumn{3}{|c|}{ Sildenafil } & \multicolumn{3}{|c|}{ Placebo } & \multicolumn{3}{|c|}{ Mean Difference } & \multirow{2}{*}{$\begin{array}{l}\text { Mean Difference } \\
\text { IV, Random, } 95 \% \mathrm{Cl}\end{array}$} \\
\hline & Mean & SD & Total & Mean & SD & Total & Weight & IV, Random, $95 \% \mathrm{Cl}$ & Year & \\
\hline Shim et.al. 2006 & -4 & 16.97 & 26 & -1 & 17.69 & 27 & $37.1 \%$ & $-3.00[-12.33,6.33]$ & 2006 & \\
\hline Candhi et.al. 2014 & 2.15 & 10.89 & 30 & -2.7 & 9.17 & 30 & $62.9 \%$ & $4.85[-0.24,9.94]$ & 2014 & \\
\hline Total $(95 \% \mathrm{Cl})$ & & & 56 & & & 57 & $100.0 \%$ & $1.94[-5.49,9.37]$ & & \\
\hline \multicolumn{10}{|c|}{$\begin{array}{l}\text { Heterogeneity: } \text { Tau }^{2}=16.10 ; C_{i}^{2}=2.09, d f=1(P=0.15) ;\left.\right|^{2}=52 \% \\
\text { Test for overall effect: } Z=0.51(P=0.61)\end{array}$} & 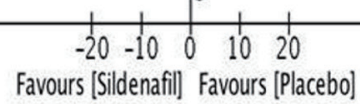 \\
\hline
\end{tabular}

Figure 8. Forest plot showing the mean difference between pre- and intra-operative MAP in the sildenafil and placebo groups. MAP: mean arterial pressure.

analysis (Fig. 5), there was a non-significant decrease in the pre-operative mPAP (mean difference of $7.41 \mathrm{~mm} \mathrm{Hg}(95 \%$ $\mathrm{CI},-21.26$ to 6.44$), \mathrm{P}<0.05)$ during the intra-operative period. There was significant heterogeneity with an $\mathrm{I}^{2}$ value of $89 \%$.

Change in pulmonary and systemic vascular resistance (PVR and SVR)

Both Shim et al [20] and Gandhi et al [22] reported changes in pulmonary and systemic vascular resistance. It was shown that pulmonary vascular resistance (Fig. 6) did not increase during the intra-operative period among those administered with pre-operative sildenafil. Rather, there was a non-significant trend towards a lower pulmonary vascular resistance (mean difference of $8.91 \mathrm{~mm} \mathrm{Hg}(95 \% \mathrm{CI},-84.02$ to 66.21$), \mathrm{P}<0.05)$ among those who received sildenafil.

Systemic vascular resistance (Fig. 7) was also not significantly affected by pre-operative administration of sildenafil (mean difference of $-43.95 \mathrm{~mm} \mathrm{Hg}$ (95\% CI, -264.68 to
176.79), $\mathrm{P}<0.05)$.

Change in mean arterial pressure (MAP)

The mean arterial pressure (Fig. 8) did not significantly decrease during the intra-operative period $(1.94 \mathrm{~mm} \mathrm{Hg}(95 \% \mathrm{CI}$, -5.49 to 9.37$), \mathrm{P}<0.05)$, but rather showed a non-significant increase in MAP among those who received pre-operative sildenafil.

\section{Mortality and post-operative outcomes}

Only two studies reported post-operative outcomes. During weaning from cardiopulmonary bypass, there were more patients in the placebo group requiring inotropic support postoperatively (Fig. 9). Those who received pre-operative sildenafil had a significant lower risk for requiring post-operative inotropic support (RR 0.38 (95\% CI, 0.20 - 0.74), P < 0.004) compared to placebo. No heterogeneity was observed.

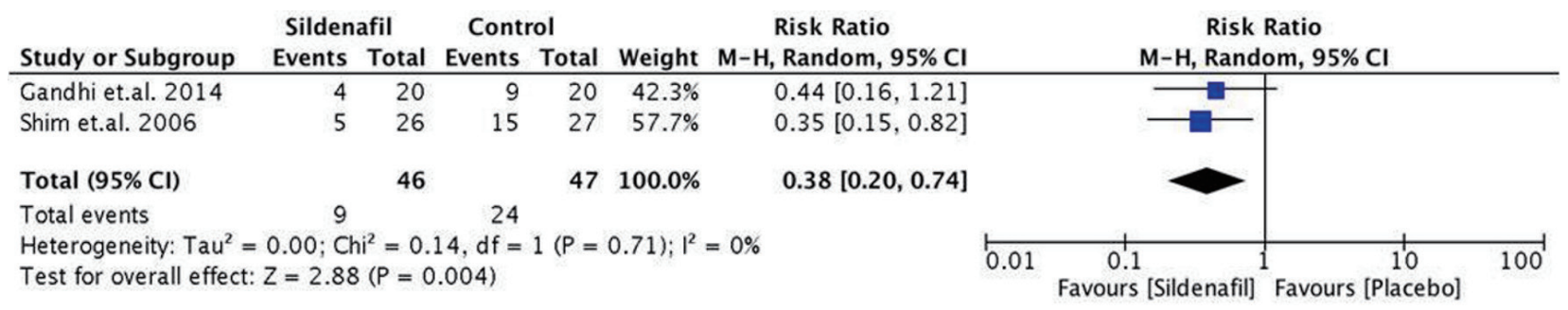

Figure 9. Forest plot showing the pooled risk ratio of pre-operative sildenafil and post-operative inotrope requirement. 
The pre-operative administration of sildenafil significantly shortened the ventilation time by $60 \mathrm{~min}(\mathrm{P}<0.001)$ and postoperative intensive care unit (ICU) stay time by $32 \mathrm{~min}(\mathrm{P}<$ 0.01 ) between the two groups as reported by Gandhi et al [22]. In the three studies included, there was only one that reported mortality in the control group.

\section{Discussion}

Cardiac surgery in patients with VHD and significant $\mathrm{PH}$ is often complicated with RV failure with an adverse consequence on its prognosis $[5,6]$. The right ventricle is susceptible to ischemic injury, as cardiopulmonary bypass exacerbates $\mathrm{PH}$ [7]. This necessitates perioperative strategy to manage $\mathrm{PH}$ and RV dysfunction. This should be achieved without compromising systemic blood pressure as well as coronary perfusion [8]. Wilkens et al [23] demonstrated that the maximal hemodynamic effects of sildenafil on pulmonary circulation could be achieved with a dose as low as $25 \mathrm{mg}$. It has a half-life of about $4 \mathrm{~h}$ and it is rapidly absorbed via the stomach and its plasma levels peak within 30 - 120 min after ingestion [24, 25].

In our study, it was shown that pre-operative sildenafil administration significantly decreased the pre-operative systolic pressure by a mean difference of $11.19 \mathrm{~mm} \mathrm{Hg}(95 \% \mathrm{CI}$, -20.23 to $-2.15 ; \mathrm{P}<0.05)$ during the intra-operative period and persisting to the post-operative period (after $1 \mathrm{~h}$ in the recovery room) with a significant mean difference of $13.67 \mathrm{~mm} \mathrm{Hg}$ (95\% CI, -19.56 to -7.78 ; $\mathrm{P}<0.05)$. During RHC, the mPAP is a more accurate measure of the pulmonary artery pressure than the systolic pulmonary pressure. Hence, in future studies, this parameter should be sought rather than the sPAP.

The mPAP (mean difference of $7.41 \mathrm{~mm} \mathrm{Hg}$ (95\% CI, -21.26 to 6.44$), \mathrm{P}<0.05)$, pulmonary vascular resistance (mean difference of $8.91 \mathrm{~mm} \mathrm{Hg}$ (95\% CI, -84.02 to 66.21), $\mathrm{P}<0.05$ ) and systemic vascular resistance (mean difference of $-43.95 \mathrm{~mm} \mathrm{Hg}(95 \% \mathrm{CI},-264.68$ to 176.79$), \mathrm{P}<0.05)$ were not significantly affected by pre-operative administration of sildenafil. It also prevented a significant rise in pulmonary vascular resistance which is expected after induction of anesthesia during cardiac surgery. This effect was also observed extending into the post-operative period. Although it showed a decreasing trend during intra-operative measurement, they did not achieve statistical significance. Possible reasons for this nonstatistical significance are the small sample size in the studies which reported these findings.

More importantly, the mean arterial pressure did not significantly decrease during the intra-operative period $(1.94 \mathrm{~mm}$ $\mathrm{Hg}(95 \% \mathrm{CI},-5.49$ to 9.37$), \mathrm{P}<0.05)$ in contrast to some other studies where hypotension was a reported adverse effect of sildenafil. Sildenafil produced significant pulmonary vasodilatation without any significant systemic effects.

Oral sildenafil is widely used in treatment of patients with erectile dysfunction and shows an excellent cardiovascular safety profile [25]. Sildenafil metabolizes the final messenger, which is cyclic guanosine monophosphate (cGMP), for vascular smooth muscle relaxation [26]. Among the various phosphodiesterases, PDE5 is the predominant type in the normal pulmonary vasculature that may be upregulated after CPB
[27]. The inhibition of PDE5 is therefore a logical step to increase the bioavailability of cGMP and support endogenous vasodilation in patient with PH. PDE5 is selectively inhibited by sildenafil, vardenafil, and tadalafil and less selectively by zaprinast and dipyridamole [28].

Only two studies reported post-operative outcomes. During weaning from cardiopulmonary bypass, there were more patients in the placebo group requiring inotropic support and ventilator support post-operatively. Those who received pre-operative sildenafil had a significant lower risk for requiring postoperative inotropic support (RR 0.38 (95\% CI, 0.20 to 0.74 ), $\mathrm{P}<0.004)$ compared to placebo while significantly shortening the ventilation time by $60 \min (\mathrm{P}<0.001)$ and post-operative ICU stay time by $32 \mathrm{~min}(\mathrm{P}<0.01)$ between the two groups. Mortality was not significantly different in the two groups.

The strength of this meta-analysis is that the selected patients in the included studies were homogenous. Almost all the patients were scheduled to undergo elective mitral valve replacement with a small number undergoing aortic valve procedure. Another important possible source of heterogeneity is the differences in the time where intra-operative parameters were measured. There was a variation of $30 \mathrm{~min}$ to $1 \mathrm{~h}$ between these measurements.

Our study has few limitations worth mentioning. First, despite observing significant mean difference between preand intra-operative SPAP, we recommend the obtaining of the mPAP during right catheterization as the more accurate measurement. Second, the included studies reported intra-operative parameters as their primary outcomes instead of clinically significant outcomes.

With the evidence presented in this meta-analysis, we therefore propose the use of pre-operative sildenafil as an inexpensive strategy to reduce the intra-operative pulmonary artery pressures among these patients. Further large studies are recommended to increase the evidence's strength on its use.

\section{Conclusions}

Our study has demonstrated that pre-operative administration of sildenafil reduces intra-operative SPAP, reduces need for post-operative inotropic support, and reduces post-operative ventilation time among patients with $\mathrm{PH}$ undergoing mitral valve replacement.

\section{Acknowledgments}

We cannot express enough thanks to our co-authors and consultant mentors for their continued support and guidance in the completion of this research. Also this would not have been easily accomplished without the support of the Division of Cardiovascular Medicine and the Department of Medicine.

\section{Financial Disclosure}

The authors did not receive any financial funding for this re- 
search project. All expenses were shouldered by the investigators of the study.

\section{Conflict of Interest}

No conflict of interest exists between the authors and any institution or pharmaceutical company.

\section{Informed Consent}

Not applicable.

\section{Author Contributions}

All authors have directly participated in the planning and analysis of this study, and have read and approved the final version submitted.

\section{References}

1. Galie N, Humbert M, Vachiery JL, Gibbs S, Lang I, Torbicki A, Simonneau G, et al. 2015 ESC/ERS Guidelines for the diagnosis and treatment of pulmonary hypertension: The Joint Task Force for the Diagnosis and Treatment of Pulmonary Hypertension of the European Society of Cardiology (ESC) and the European Respiratory Society (ERS): Endorsed by: Association for European Paediatric and Congenital Cardiology (AEPC), International Society for Heart and Lung Transplantation (ISHLT). Eur Heart J. 2016;37(1):67-119.

2. Weitsman T, Weisz G, Farkash R, Klutstein M, Butnaru A, Rosenmann D, Hasin T. Pulmonary Hypertension with Left Heart Disease: Prevalence, Temporal Shifts in Etiologies and Outcome. Am J Med. 2017;130(11):12721279.

3. Baumgartner H, Falk V, Bax JJ, De Bonis M, Hamm C, Holm PJ, Iung B, et al. 2017 ESC/EACTS Guidelines for the management of valvular heart disease. Eur Heart J. 2017;38(36):2739-2791.

4. Magne J, Pibarot P, Sengupta PP, Donal E, Rosenhek R, Lancellotti P. Pulmonary hypertension in valvular disease: a comprehensive review on pathophysiology to therapy from the HAVEC Group. JACC Cardiovasc Imaging. 2015;8(1):83-99.

5. Ward C, Hancock BW. Extreme pulmonary hypertension caused by mitral valve disease. Natural history and results of surgery. Br Heart J. 1975;37(1):74-78.

6. Malouf JF, Enriquez-Sarano M, Pellikka PA, Oh JK, Bailey KR, Chandrasekaran K, Mullany CJ, et al. Severe pulmonary hypertension in patients with severe aortic valve stenosis: clinical profile and prognostic implications. J Am Coll Cardiol. 2002;40(4):789-795.

7. Mangano DT. Biventricular function after myocardial revascularization in humans: deterioration and recov- ery patterns during the first 24 hours. Anesthesiology. 1985;62(5):571-577.

8. Calvin JE, Jr. Acute right heart failure: pathophysiology, recognition, and pharmacological management. J Cardiothorac Vasc Anesth. 1991;5(5):507-513.

9. Ghoreishi M, Evans CF, DeFilippi CR, Hobbs G, Young CA, Griffith BP, Gammie JS. Pulmonary hypertension adversely affects short- and long-term survival after mitral valve operation for mitral regurgitation: implications for timing of surgery. J Thorac Cardiovasc Surg. 2011;142(6):1439-1452.

10. Michelakis E, Tymchak W, Lien D, Webster L, Hashimoto $\mathrm{K}$, Archer S. Oral sildenafil is an effective and specific pulmonary vasodilator in patients with pulmonary arterial hypertension: comparison with inhaled nitric oxide. Circulation. 2002;105(20):2398-2403.

11. Galie N, Ghofrani HA, Torbicki A, Barst RJ, Rubin LJ, Badesch D, Fleming T, et al. Sildenafil citrate therapy for pulmonary arterial hypertension. N Engl J Med. 2005;353(20):2148-2157.

12. Redfield MM, Chen HH, Borlaug BA, Semigran MJ, Lee KL, Lewis G, LeWinter MM, et al. Effect of phosphodiesterase-5 inhibition on exercise capacity and clinical status in heart failure with preserved ejection fraction: a randomized clinical trial. JAMA. 2013;309(12):1268-1277.

13. Lewis GD, Lachmann J, Camuso J, Lepore JJ, Shin J, Martinovic ME, Systrom DM, et al. Sildenafil improves exercise hemodynamics and oxygen uptake in patients with systolic heart failure. Circulation. 2007;115(1):59-66.

14. Guazzi M, Vicenzi M, Arena R. Phosphodiesterase 5 inhibition with sildenafil reverses exercise oscillatory breathing in chronic heart failure: a long-term cardiopulmonary exercise testing placebo-controlled study. Eur J Heart Fail. 2012;14(1):82-90.

15. Cooper TJ, Guazzi M, Al-Mohammad A, Amir O, Bengal T, Cleland JG, Dickstein K. Sildenafil in Heart failure (SilHF). An investigator-initiated multinational randomized controlled clinical trial: rationale and design. Eur J Heart Fail. 2013;15(1):119-122.

16. Hoendermis ES, Liu LC, Hummel YM, van der Meer P, de Boer RA, Berger RM, van Veldhuisen DJ, et al. Effects of sildenafil on invasive haemodynamics and exercise capacity in heart failure patients with preserved ejection fraction and pulmonary hypertension: a randomized controlled trial. Eur Heart J. 2015;36(38):2565-2573.

17. Trachte AL, Lobato EB, Urdaneta F, Hess PJ, Klodell CT, Martin TD, Staples ED, et al. Oral sildenafil reduces pulmonary hypertension after cardiac surgery. Ann Thorac Surg. 2005;79(1):194-197; discussion 194-197.

18. Jiang G, Li B, Zhang G, Xu E, Liu Y, Xu Z. Effects of sildenafil on prognosis in patients with pulmonary hypertension after left-sided valvular surgery. Heart Lung Circ. 2014;23(7):680-685.

19. Bermejo J, Yotti R, Garcia-Orta R, Sanchez-Fernandez PL, Castano M, Segovia-Cubero J, Escribano-Subias P, et al. Sildenafil for improving outcomes in patients with corrected valvular heart disease and persistent pulmonary hypertension: a multicenter, double-blind, randomized clinical trial. Eur Heart J. 2018;39(15):1255-1264. 
20. Shim JK, Choi YS, Oh YJ, Kim DH, Hong YW, Kwak YL. Effect of oral sildenafil citrate on intraoperative hemodynamics in patients with pulmonary hypertension undergoing valvular heart surgery. J Thorac Cardiovasc Surg. 2006;132(6):1420-1425.

21. Ayyad M, Abdel-Geleel A. Effect of immediate preoperative oral sildenafil administration for pulmonary hypertension in patients undergoing valve replacement. Journal of the Egyptian Society of Cardio-Thoracic Surgery. 2012;20(1-2):113-117.

22. Gandhi H, Shah B, Patel R, Toshani R, Pujara J, Kothari J, Shastri N. Effect of preoperative oral sildenafil on severe pulmonary artery hypertension in patients undergoing mitral valve replacement. Indian J Pharmacol. 2014;46(3):281-285.

23. Wilkens H, Guth A, Konig J, Forestier N, Cremers B, Hennen B, Bohm M, et al. Effect of inhaled iloprost plus oral sildenafil in patients with primary pulmonary hyper- tension. Circulation. 2001;104(11):1218-1222.

24. Prasad S, Wilkinson J, Gatzoulis MA. Sildenafil in primary pulmonary hypertension. N Engl J Med. 2000;343(18):1342.

25. Boolell M, Allen MJ, Ballard SA, Gepi-Attee S, Muirhead GJ, Naylor AM, Osterloh IH, et al. Sildenafil: an orally active type 5 cyclic GMP-specific phosphodiesterase inhibitor for the treatment of penile erectile dysfunction. Int J Impot Res. 1996;8(2):47-52.

26. Rabe KF, Tenor H, Dent G, Schudt C, Nakashima M, Magnussen H. Identification of PDE isozymes in human pulmonary artery and effect of selective PDE inhibitors. Am J Physiol. 1994;266(5 Pt 1):L536-543.

27. Giaid A, Saleh D. Reduced expression of endothelial nitric oxide synthase in the lungs of patients with pulmonary hypertension. N Engl J Med. 1995;333(4):214-221.

28. Raja SG, Nayak SH. Sildenafil: emerging cardiovascular indications. Ann Thorac Surg. 2004;78(4):1496-1506. 